International Journal of Multidisciplinary Studies and Innovative Research

Publisher: Catholic University College of Ghana

ISSN: 2737-7172 (0), ISSN: 2737-7180 (P)

DOI: $10.53075 /$ ljmsirq5930716

DOI Url: http://doi.org/10.53075/ljmsirq5930716

\title{
EVALUATION OF THE IMPLEMENTATION OF ELECTRONIC HEALTH RECORD SYSTEM: CASE STUDY OF THE PRESBYTERIAN HOSPITAL AT DORMAA AHENKRO OF BONO REGION, GHANA
}

\author{
Rita Frimpong \\ Department of Computer science, Kwame Nkrumah University of Science and Technology: ritafrimpong200@gmail.com \\ Copyrights \\ Copyright for this article is retained by the author, with first publication rights granted to the journal. This is an open-access article \\ distributed under the terms and conditions of the Creative Commons Attribution license (http://creativecommons.org/licenses/by/4.0/)
}

Received: November 1, 2021 Accepted: November 19, 2021 Published Online: November 22, 2021

\begin{abstract}
The main objective of this study is to evaluate the implementation of electronic health records at Presbyterian Hospital in Dormaa Ahenkro, Bono Region, Ghana. A total sample size of 50 staff and management of the hospital were sampled using the purposive sampling technique. Qualitative data was collected using questionnaires and observational checklists enlisting the workings of the facilities or technology, while quantitative data was captured using Key Informant Interview (KII) guides with key management staff of the hospital. Data analysis was done descriptively using the Statistical Package for Social Sciences software (SPSS version 21.0). The study revealed that factors such as expectancy of performance, anticipation or effort, facilitating conditions, and social influence highly influence the management of the hospital to adopt the technology. The study revealed that frequent power outages are the main challenge they are confronted with. The study recommended that management implement safeguards to ensure the system stands against loss, destruction, interfering, and unlawful use of the EHR system. System safeguards must be in place. Management through the IT unit should consider procurement of an efficient backup system and regular change of passwords to maintain the security of the system.
\end{abstract}

Keywords: Electronic health records, evaluate, implementation, health care delivery, hospital management

\section{INTRODUCTION}

In the developing world, governments have attempted to increase access and quality of health delivery through health information (Baumann et al., 2018). World Health Organization (WHO, 1998) recognizes the likely beneficial returns of employing ICT in the administration of healthcare. In the Health-For-All Strategy, the organization recommended member states to "make use of health telematics as they integrate appropriately into the overall policy and strategy to provide health in the $21^{\text {st }}$ century for all. This is to fulfil the vision of a world in which the benefits of science, technology and public health growth are made equally accessible to people globally" (Garcelon et al., 2020). Again, WHO has resolved through WHA58.28, to encourage member states to draw long-term strategic plans for eHealth services.

Electronic Health Records is part of the broader E-health which includes the growth and the use of numerous ICT schemes for health care (Zhang et al., 2018). World Health Organization (WHO), (2006) defines EHR as a lengthy and electronic collection of health information involving persons in different sectors and institutions about information relating to the health of an individual. The patients' demographic reports, patients' medical history, progress report, patient's complaints, administered medication, laboratory reports and radiology reports are all type of information available in the records (Rambaud-Althaus et al., 2017). Findings from Zang et al., (2018) indicates that EHR systems are efficient, cut down on serious medication errors significantly, improve users' assessing information of patients. During crises, access to patient information is provided by the EHR systems without necessarily needing the bodily 


\title{
International Journal of Multidisciplinary Studies and Innovative Research
}

\author{
Publisher: Catholic University College of Ghana \\ ISSN: 2737-7172 (0), ISSN: 2737-7180 (P) \\ DOI: $10.53075 /$ ljmsirq5930716 \\ DOI Url: http://doi.org/10.53075/ljmsirq5930716
}

presence of the sick individual (Hansen et al., n.d.). According to (Garcelon et al., 2020), medical informatics has (EHR) is a vital component as it assists health providing facilities to promote quality patient healthcare and client safety. The authors further argue that the system also potentially reduces the cost incurred and improves workplace efficiency. There are distinct advantages in using electronic records as against paper records. According to (Fragidis \& Chatzoglou, 2018), these advantages include but are not limited to enabling assessing medical records in less deprived areas, improving the ease as well as the speed at which records are retrieved. Others include avenues to raise the flag of abnormal results and being able to eliminate handwritten prescriptions. Moreover, it reduces cases of errors in prescription as always seen in healthcare facilities. Furthermore, there are advantages of the system being able to access records of patients simultaneously by several users at a time, and the option to perform queries on available data leading to making decisions. The potential positives of EHR have led to wide acceptance by many in industrialized nations (Agniel et al., 2018).

In Ghana, many reforms are been made in the management of health data systems with the view of improving the quality of health information, which is concerning demands from donor agents including the UNDP (Abul-Husn \& Kenny, 2019). Amongst the numerous Health Management Information Systems (HMIS) interventions, the Maternal and Child Health Information System is supported by the UNDP. Since 2007, one of the earlier attempts of Ghana to modernize health information capture through ICT is the use of the District Health Information Management System (DHIMS). The software is used to collect data with the sole purpose of management and development of policies. Data collected is sent to regional health administrations for analysis and further forwarded to the National Health Administration (the Ghana Health Service [GHS] and/or the Ministry of Health). In 2010, a national policy on e-health was formulated in Ghana and has been in operation since. No regulation exists on individual and health data which will promote confidentiality of personally recognizable data and further guard personally perceptible data explicitly in EHR (Abul-Husn \& Kenny, 2019). The low level of e-health deployment in the health sector generally according to the Ministry of Health (2010) is due to limited investment in ICT, lacking human resources, and the awkward nature of health information systems placement are key problems to operative health information systems.

Electronic health record (EHR) is an important tool for improving patient's access to information with resulting in improvement in quality of care. Sub-Saharan Africa countries including Ghana however have not widely adopted and implemented EHR. The World Health Organization (2006) identified a number of obstacles that impede the smooth adaptation and implementation of EHR in most developing countries. Among the many obstacles are the existence of technology but lack practical sustenance and the luxury of moving to a system of electronically coupled with inadequate finances of health delivery. Elsewhere in developing nations, expenses, technology availability, practical know-how and information technology abilities of workers, and inadequate facilities for processing data (WHO, 2006). While all these are critical in the adoption process, some health professionals and medical practitioners have strongly refused to adjust from manual to electronic documentation.

In developing countries, due to limited human and financial resources, it is difficult to meet the demand for equitable and quality healthcare. A developing country such as Ghana is not excluded and thus, contends with the issue of providing for its citizens equal and value health delivery. It is not uncommon as most of the health centers across the country use the hard copy file system for processing and storing of data and information, particularly with regards to patient's data such as personnel records is the routine practice. While the world is moving towards computerbased processing and storage of information, the same cannot be said of electronic health records such as patient data in digital form, storage and exchange. In some instances, patients have to be given a new card. During retrieval of such cards, it takes the OPD attendant to search for a patient card in a poorly arranged file desk. This situation sometimes results in loss of productive periods for patients and most at times, the history of the patient cannot be traced. This frustration results in poor healthcare delivery. Implementing an EHR system could go a long way to address the breaks of insufficient access and deprived healthcare delivery significantly. Since 2015, the Presbyterian Hospital in Dormaa Ahenkro deployed EHR which is based on the hospital-based environment in the healthcare 
International Journal of Multidisciplinary Studies and Innovative Research

\author{
Publisher: Catholic University College of Ghana \\ ISSN: 2737-7172 (0), ISSN: 2737-7180 (P) \\ DOI: $10.53075 /$ ljmsirq5930716 \\ DOI Url: http://doi.org/10.53075/ljmsirq5930716
}

delivery and services as used to facilitate or improve present workflows. However, to implement an innovative (such as EHR), especially in multifaceted work settings typically as health area requires care and a well-supposed idea and approach to address the challenges. Additionally, many studies have not been done on the limiting factors for the execution of EHR in other allied facilities within the region. The extent and type of automation, however, is not known. Various researches have been undertaken in EHR in hospital settings in Ghana but concentrated on Teaching Hospitals and particularly a major referral health centers. However, the recent studies have not explored the usage of EHR technology in a seemingly low urban setting and how it affects the delivery of healthcare in the hospital, staff and the entire populace. Thus, the role of electronic health records and how it improves health care delivery in the Dormaa Presbyterian hospital in the Bono Region are an under-explored area.

The main objective of this study is to evaluate the implementation of electronic health records at Presbyterian hospital in Dormaa Ahenkro of Bono Region, Ghana. The Specific objectives are:

- Examine the factors influencing the deployment of EHR in the hospital healthcare services and delivery at Presbyterian Hospital of Dormaa Ahenkro.

- Examine the extent to which EHR affect healthcare delivery, the associated problems and measures to deal with the system at Presbyterian Hospital of Dormaa Ahenkro.

Over the past 63 years, the Presbyterian Hospital in Dormaa Ahenkro which remains the Municipal Hospital in Dormaa Central Municipality in the Bono region provides general patients care to the people, also specializes in orthopaedics in Bono Region. As a municipal hospital and orthopaedics center, it receives referral cases from health centers in the municipality and other two districts (Dormaa West and Dormaa East) and orthopedics cases from the entire region. Though a Presbyterian mission health facility, the government through the Ghana Health Service has some responsibility over the facility through the provision of human resource, infrastructure support and subventions for the running of the facility. The hospital operates Out-patient Department (OPD) and an In-patient Department. It operates various ward units, these units are, Pediatric Ward, Maternity Clinic, Surgical Ward (Male/ female), Causality Ward, Intensive Care Unit, and the Gynaecology Ward. The hospital's bed capacity stands at 216 and the total staff number is about 547. Students such as nurses, health services planners and paramedics also receive practical training at the facility.

\title{
2. MATERIALS AND METHODS
}

\section{Study Design}

The mixed method cross-sectional research design was used basically under this study which employed the use of both the qualitative and the quantitative data collection methods respectively. Mixed method design broadly and more completely answers wide variety of research questions. The main reason for the use of mixed methods research was generously in terms of completeness, in that a more comprehensive picture would be generated. For constructivists the main aim is to gain rich and accurate insights of the complexity of social issues. Quantitative data was collected using questionnaires and observational checklist enlisting the workings of the facilities or technology while Qualitative data was captured using Key Informants Interview (KII) guides with key management staff of the hospital.

\section{Study Population}

The target populations under this study are the Staff and Management of the Presbyterian Hospital among the people of Dormaa Ahenkro in the Region of Bono. Those under the study population included all the staff in the various units and users of the EHR. Presbyterian Hospital's population of permanent employees ranging from medical staff, administrative staff, auxiliary workers etc. is 100. Management of the hospital is 15 (the Medical Director, Administrator, HR, Matron, Finance, Pharmacist, and Laboratory). 


\title{
International Journal of Multidisciplinary Studies and Innovative Research
}

\author{
Publisher: Catholic University College of Ghana \\ ISSN: 2737-7172 (0), ISSN: 2737-7180 (P) \\ DOI: $10.53075 /$ ljmsirq5930716 \\ DOI Url: http://doi.org/10.53075/ljmsirq5930716
}

\section{Sample Selection Procedures}

When research studies take place in natural or field settings, choosing a site or institution for a study is probably a difficult part of doing any research study (qualitative and/or quantitative) as the site finally chosen must be willing for the researcher to intrude on its territory (Cortina, 2020). Cortina, (2020) posits that, the site being selected for the study should be the one that is possible to enter; a high likelihood or chance with a mixture of process, people, programme, interactions, and structures of interest; there is the real likelihood of building trusting relations; and finally, the quality of data and there is the assurance of credibility of the study findings. For this research, the selection of Presbyterian Hospital, Dormaa Ahenkro in the region of Bono as the research site was based on the above guidelines. Again, proximity to the study hospital was also considered to make it possible for the researcher's availability of resources, which include time and money in other to complete the research work under study successfully.

In addition to the above, the choice of the study health facility was also based on such criteria as proximity to ensure easy communication, knowledge of the hospital to ensure easy access to information in the implementation of the project.

\section{Sources of Data}

Sources of data under this study are both primary and secondary. Primary sources of data were purposely used for a specific task or specific research under the study. The primary data was obtained from the main target of the population from the study. According to Myers (2009), secondary data concerns previously published data relevant to the current study. The literature reviewed mostly constituted the secondary data which supported the primary sources of data collected from the main target participants under study. The researcher was able to carry out these empirical investigations on the discovery of electronic health facility records through the study institution make use of both primary and secondary sources of data from other research studies.

\section{Data Collection Instruments}

For easily achieving of the objectives under study, both questionnaires and structured interviews were selected and used as methods for the data collection. Using a combination of diverse data collection methods according to (AbulHusn \& Kenny, 2019) in one study aid triangulation and is more likely to the final result of the work was well used and studied. The questionnaires used were composed of closed and open-ended questions that were intended specifically to those that answered the questionnaires distributed, a choice and also the opportunity to provide diverse answers on the research questions. The factors which motivated the choice of a research questionnaire were that (a) it was easy to carry out analysis and comparisons, (b) it was easy to understand, especially since the questions were clear without any ambiguity. A semi-structured interview is adopted for this research and it provided the study with some advantages. This includes providing an in-depth understanding of the situation within this context is imperative for the analysis. The semi-structured organization nature of the interviews requires that the respondents were asked a series of questions but with the flexibility for adjustment in response to its development. Thus, questions could be framed and extra questions could be asked when they are subjected to the questions under study. All the interview sessions were recorded using an electronic voice recorder

\section{Analysis of Data}

The data analysis collected was obtained from both quantitative and qualitative approaches. The adoption of these approaches is based on the mixed method that allowed for multiple sources of data collection such as questionnaires and interviews. Quantitative data was mostly collected after the survey and the data obtained was well edited and coded to avoid any statistical error after the analysis. The researcher coded the data into categories before entering them on the Statistical Package for Social Sciences software (SPSS version 21.0) as numerals were assigned to each of the items. The SPSS programmer generated the quantitative results which include; the percentages, the frequencies as well as means and averages. Qualitative data was also analyzed thematically. 


\title{
International Journal of Multidisciplinary Studies and Innovative Research
}

\author{
Publisher: Catholic University College of Ghana \\ ISSN: 2737-7172 (0), ISSN: 2737-7180 (P) \\ DOI: $10.53075 /$ ljmsirq5930716 \\ DOI Url: http://doi.org/10.53075/ljmsirq5930716
}

\section{Ethical Considerations}

The study was thoroughly organized following distinct ethical rules and regulations. Specific issues addressed included approval to conduct the work, consent from the Presbyterian Hospital, Dormaa Ahenkro and respondents and ensuring credible results from the study. A permission letter was sort from the management of the hospital to enable the researcher to further seek consent from the relevant respondents who were subsequently assured of confidentiality and anonymity in the entire process of the study.

\section{RESULTS AND DISCUSSION}

\section{Biographic Information of Respondents}

This subsection presents the background information of the study participants (staff and management). These included distributions on: gender, age, educational qualification and number of years in the hospital. The description on the socio-demographic and on the economic characteristics of respondents is meant to inquire the readers of this study to the various characteristics of the respondents and the main context within which interviews were conducted and obtained.

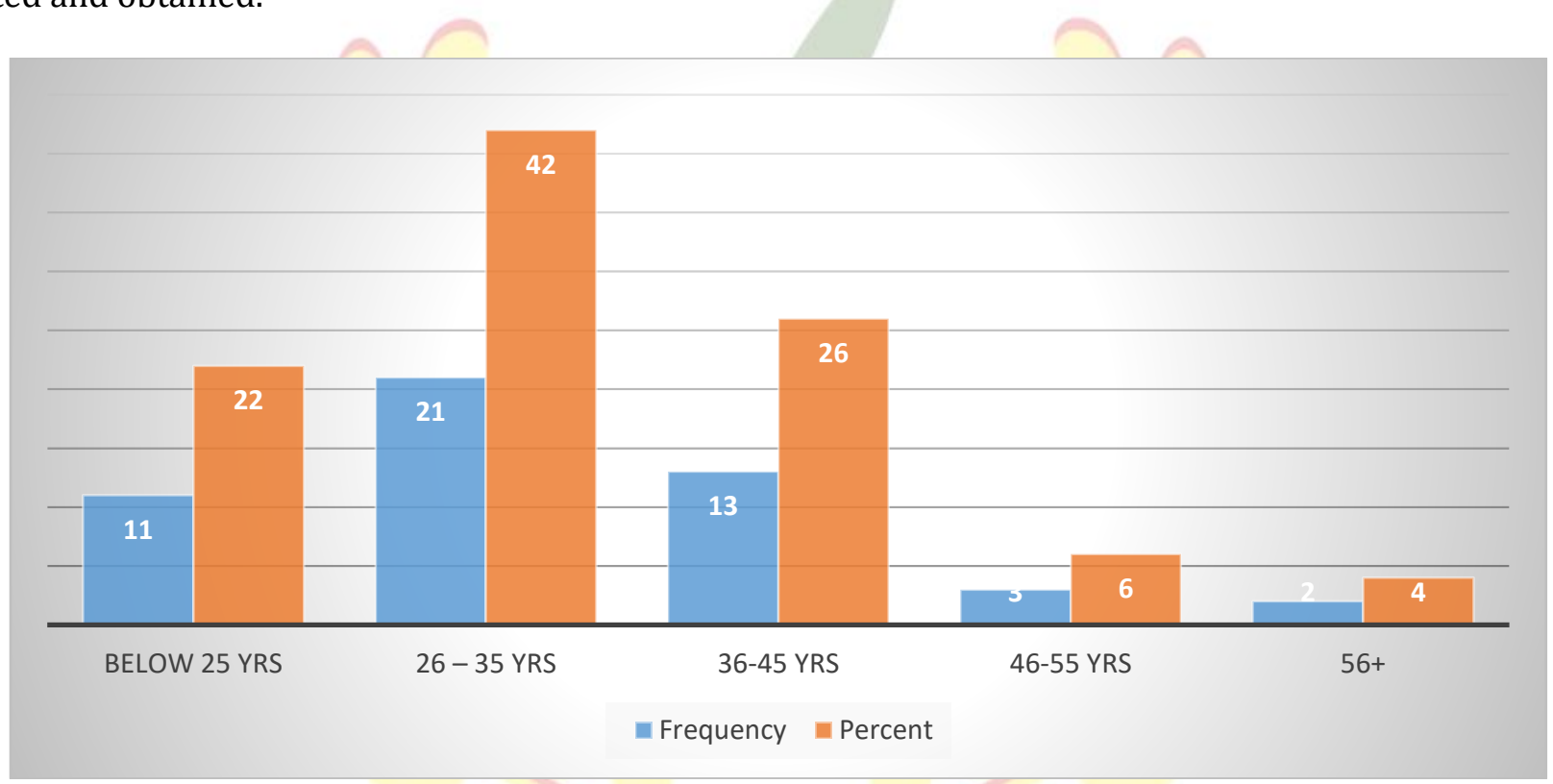

Source: Fieldwork, July 2019

\section{Figure 1: Age of Respondents}

The age group with the highest percentage (42\%) was 26-35 of the respondents. This was followed by those in the age groupings 36-45 with a percentage score of 26\%. Twenty-two percent of those who were surveyed and questioned were below of 25 years of age. Those of the remaining respondents $6 \%$ and $4 \%$ were in the age brackets between 46-55 years and above 56 years respectively. 
International Journal of Multidisciplinary Studies and Innovative Research

Publisher: Catholic University College of Ghana

ISSN: 2737-7172 (0), ISSN: $2737-7180(P)$

DOI: $10.53075 /$ ljmsirq5930716

DOI Url: http://doi.org/10.53075/ljmsirq5930716

\section{Table 1: Gender Distribution of Respondents}

\begin{tabular}{|l|c|c|}
\hline Gender & Frequency & Percent \\
\hline Male & 19 & 38.0 \\
\hline Female & 31 & 62.0 \\
\hline Total & 50 & 100.0 \\
\hline
\end{tabular}

Source: Fieldwork, July 2019

As portrayed by the data in Table 1, displays that most of the respondents represented by $62 \%$ were female. This is largely true because most of the areas that this system is deployed are mostly female-dominated.



Source: Fieldwork, July 2019

Figure 2: Various Educational levels of respondents

Figure 2 shows that all the respondents have tertiary education ranging from diploma to post-graduate certificates from tertiary institutions. Half of the respondents are degree holders with different course areas. Those with Diploma certificates constitute $22 \%$ of the respondents interviewed. During the data analysis, it was revealed that $18 \%$ of the respondents have post-graduate certificates (Masters) and one-tenth also hold specialized certificates who are mainly Medical Doctors. 
International Journal of Multidisciplinary Studies and Innovative Research

Publisher: Catholic University College of Ghana

ISSN: 2737-7172 (0), ISSN: $2737-7180(P)$

DOI: $10.53075 /$ ljmsirq5930716

DOI Url: http://doi.org/10.53075/ljmsirq5930716

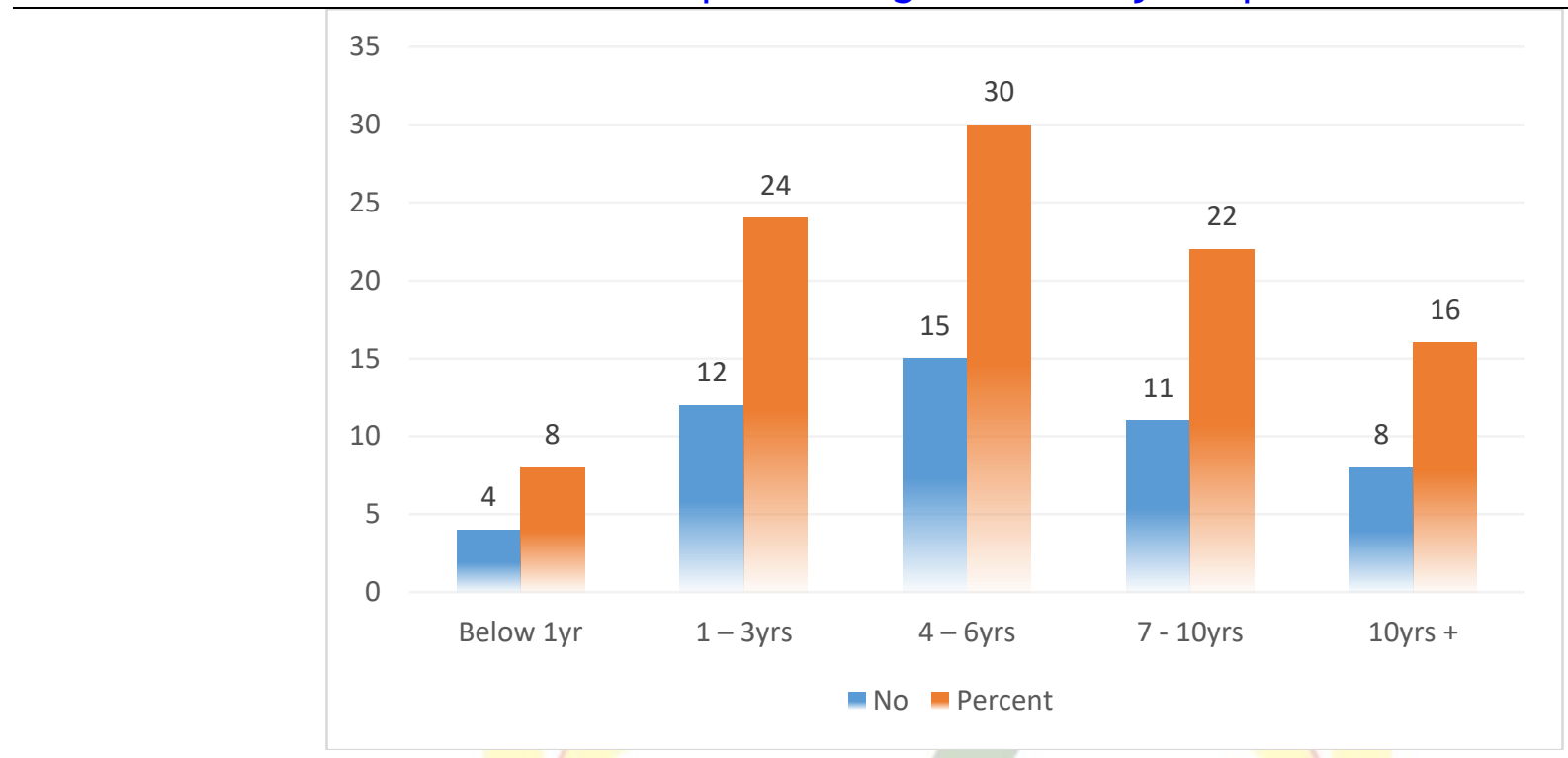

Source: Fieldwork, July 2019

Figure 3: Working experiences of Respondents

Data in Figure 3 indicates that 30\% of the respondents representing the majority have a length of service with the hospital between 4-6 years. While $24 \%$ of the respondents have work experience between 1 to 3 years, $22 \%$ have between 7 to 10 years of work experience at the hospital. Those with the highest period of years working in the hospital (more than 10 years) constitute 16\%. Less than one-tenth of the respondents representing $8 \%$ have the least number of years in the health facility, thus, below a year.

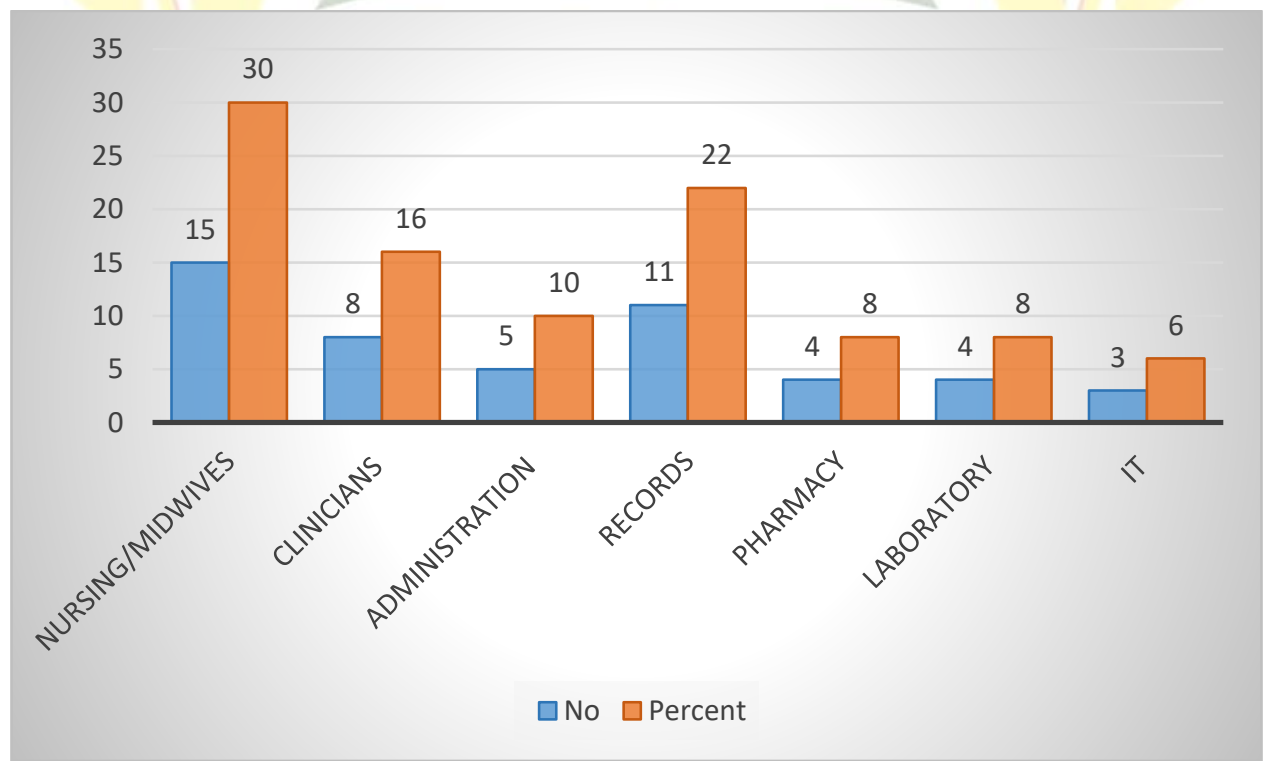

Source: Fieldwork, July 2019

Figure 4: Professional backgrounds of Respondents 


\title{
International Journal of Multidisciplinary Studies and Innovative Research
}

\author{
Publisher: Catholic University College of Ghana \\ ISSN: 2737-7172 (0), ISSN: 2737-7180 (P) \\ DOI: $10.53075 /$ Ijmsirq5930716 \\ DOI Url: http://doi.org/10.53075/ljmsirq5930716
}

Figure 4 shows that the highest percentage of respondents represented by (30\%) were taken from the nurses and midwives, $22 \%$ of respondents from the record officers, $16 \%$ of respondents also from the Clinicians, $10 \%$ of respondents were Administrative Staff, $8 \%$ each were Laboratory staff, and Pharmacy staff. The least were IT staff who constituted $6 \%$.

\section{Factors influencing the deployment of the electronic health records in the Hospital}

This subsection requires that the study presents the results on data analyzed generating the factors that suggests the deployment of EHR in the hospital. Five factors were used to measure the factors that influence the deployment and essence of EHR in the hospital. These factors ranged from characteristics of the personnel and the hospital to the factors identified in the literature. These factors include health care provider characteristics, performance expectancy, effort expectancy, social influence and facilitating conditions. Also, their sub-themes have additional subthemes which were developed as a result of the analysis and comparison of field data.

Table 2: Health care provider characteristics related factors

\begin{tabular}{|l|c|c|}
\hline Independent Variables & Mean & Std. Dev. \\
\hline Years in practice (experience of the staff) & 4.9655 & .18570 \\
\hline IT knowledge and literacy & 5.0000 & .0000 \\
\hline Age of the user & 1.1667 & .38348 \\
\hline Gender of the user & 1.1667 & .38348 \\
\hline
\end{tabular}

Source: Field survey, (2019)

Table 2 shows the user knowledge and literacy in IT very highly influenced the adoption of EHR in the hospital (5.0000) and the number of years in practice as a health worker also very highly influenced the use of the technology. This is the reason why management before the introduction of systems like this, organizes training programmes to equip them. However, few of the respondents indicated age and gender of the users have low influence in the adoption of the EMR system (1.1667).

Table 3: Performance expectancy related factors

\begin{tabular}{|l|c|c|}
\hline Independent Variables & Mean & Std. Dev. \\
\hline There is a perceived usefulness of the technology & 4.7241 & .45486 \\
\hline The technology enhances the efficiency of the service & 4.9655 & .18570 \\
\hline $\begin{array}{l}\text { The technology enhances accessibility and communication } \\
\text { with the patient }\end{array}$ & 5.0000 & .0000 \\
\hline The technology has enhanced customer satisfaction & 4.9655 & .18570 \\
\hline
\end{tabular}

Source: Field survey, (2019)

Using a Likert scale format with the scale of very high influence (5), high influence (4) moderate influence (3), low influence (2) or no influence (1), Table 3 shows that the respondents indicated that there is a very high influence with the usefulness of the technology (4.7241). Also, there was a very high influence of the technology promoting the efficiency of the service provided by the system (4.9655). Additionally, the following statements had a very high influence on the adoption of the EHR: the technology helps accessibility and effective communication with patients (5.0000), and it has enhanced customer satisfaction with the care received (4.9655). 
International Journal of Multidisciplinary Studies and Innovative Research

\author{
Publisher: Catholic University College of Ghana \\ ISSN: 2737-7172 (0), ISSN: $2737-7180(P)$ \\ DOI: $10.53075 /$ ljmsirq5930716 \\ DOI Url: http://doi.org/10.53075/ljmsirq5930716
}

In summary, there are a very high influence of performance expectancy related factors on the adoption of the EHR in the hospital's care services.

Table 4: Effort expectancy related factors

\begin{tabular}{|l|c|c|}
\hline Independent Variables & Mean & Std. Dev. \\
\hline There is usability of the technology & 4.8966 & .30993 \\
\hline The system is up-to-date & 4.2069 & .41225 \\
\hline The technology is self-solving when an error occurs & 4.7931 & .41225 \\
\hline The technology helps facilitate service & 4.8966 & .30993 \\
\hline
\end{tabular}

Source: Field survey, (2019)

With regard to effort expectancy related factors influencing the adoption of the technology, Table 4 displays that there was general acceptance by respondents that the usability of the technology has a very high influence on the adoption of the EHR in the hospital care services, and helps facilitate the services provided in the hospital (4.8966). Again, the respondents believed that the self-solving mechanism in the technology very highly influenced the decision by management to adopt the system (4.7931). The results also indicate that the system being up-to-date highly influenced the adoption of the technology. It can be concluded that there is a very high influence of the effort expectancy related factors regarding the adoption of the technology into the facility's care services.

Table 5: Social influence related factors

\begin{tabular}{|l|c|c|}
\hline Independent Variables & Mean & \multicolumn{1}{l|}{ Std. Dev. } \\
\hline There is an IT Specialist specifically for the EHR set up & 5.0000 & .0000 \\
\hline $\begin{array}{l}\text { Both staff and management support the deployment of } \\
\text { the technology }\end{array}$ & 4.6552 & .48373 \\
\hline $\begin{array}{l}\text { The organizational setting supports the change brought } \\
\text { up by the technology }\end{array}$ & 5.0000 & .0000 \\
\hline The IT Specialist has a high level of experience & 3.2055 & .77364 \\
\hline
\end{tabular}

Source: Field survey, (2019)

Table 5 shows that the respondents perceived a very high influence of the availability of IT Specialist specifically for the technology set up, and the organizational setting supporting the change as the need for the adoption of the EHR technology in the hospital care services (5.0000). Again, both management and staff support highly influenced the deployment and utilization of the EHR technology (4.6552). The extent to which the experience of the IT specialist influenced the adoption of the technology was however moderate as indicated by the respondents (3.2055). Per the results, social influence related factors influenced the decision by the management of the hospital to deploy the EHR technology in the hospital care services. 
International Journal of Multidisciplinary Studies and Innovative Research

Publisher: Catholic University College of Ghana

ISSN: 2737-7172 (O), ISSN: 2737-7180 (P)

DOI: $10.53075 /$ ljmsirq5930716

DOI Url: http://doi.org/10.53075/ljmsirq5930716

Table 6: Facilitating conditions related factors

\begin{tabular}{|l|c|c|}
\hline Independent Variables & Mean & Std. Dev. \\
\hline $\begin{array}{l}\text { There is availability of IT tools such as hardware and } \\
\text { software equipment }\end{array}$ & 5.0000 & .0000 \\
\hline There is constant flow of power to enable it usage & 1.1667 & .38348 \\
\hline $\begin{array}{l}\text { There is regular training of staff about the system and how } \\
\text { to use it }\end{array}$ & 5.0000 & .0000 \\
\hline $\begin{array}{l}\text { There is IT department to oversee the management of the } \\
\text { technology }\end{array}$ & 5.0000 & .0000 \\
\hline
\end{tabular}

Source: Field survey, (2019)

The results in Table 6 show that the following factors in a very highly influenced management to adopt the technology in the hospital system; availability of IT tools such as hardware and software equipment, regular training of staff about the system and how to use it, and an IT department to oversee the management of the technology (5.0000). However, there was no influence about the flow of electricity which made the management to deploy the technology.

Table 7: Type of Information captured by the technology

\begin{tabular}{|l|c|c|}
\hline Specific information & No. & Percent \\
\hline Patients' demographics & 4.7241 & .45486 \\
\hline Past medical records or history of patients & 4.9655 & .18570 \\
\hline Patients' progress report & 5.0000 & .0000 \\
\hline Patient medical history and other results & 4.9655 & .18570 \\
\hline
\end{tabular}

Source: Field survey (2019)

Table 7 shows that EHR contains the patient's progress report (5.0000), the patient's medical history and other results (4.9655), and the past medical records of the patients (4.9655). almost all the respondents indicated that the system contains the patient's biodata (4.7241).

Extent to which electronic health records affect the health care delivery and services in the Hospital This objective sought to understand from the staff and management how the technology has facilitated health care procedures and services in the health facility.

Table 8: Best description of the technology from results produced

\begin{tabular}{|l|c|c|}
\hline Attributes & No & Percent \\
\hline Accessible & 21 & 46.7 \\
\hline Efficient & 5 & 11.1 \\
\hline Reduction in errors & 8 & 17.8 \\
\hline Accurate & 9 & 20.0 \\
\hline Reliable & 2 & 4.4 \\
\hline Total & 45 & 100 \\
\hline
\end{tabular}

Source: Fieldwork, 2019 
International Journal of Multidisciplinary Studies and Innovative Research

Publisher: Catholic University College of Ghana

ISSN: 2737-7172 (O), ISSN: 2737-7180 (P)

DOI: $10.53075 /$ ljmsirq5930716

DOI Url: http://doi.org/10.53075/ljmsirq5930716

Table 8 depicts the respondents' best description of the system they are operating with. Most of the respondents $(46.7 \%)$ said the system is accessible (accessibility). One-fifth of the respondents said it is accurate (accuracy). Reducing errors came next as $17.8 \%$ of the respondents mentioned that as a feature. Others, $11.1 \%$ said the system is efficient (efficiency) while $4.4 \%$ said the technology is reliable (reliability).

Table 9: Extent to which EHR makes work easier and faster

\begin{tabular}{|l|c|c|}
\hline Responses & No & Percent \\
\hline A very large extent & 7 & 15.6 \\
\hline A large extent & 20 & 44.4 \\
\hline Some extent & 13 & 28.9 \\
\hline A very small extent & 5 & 11.1 \\
\hline Not at all & 0 & 0.0 \\
\hline Total & 45 & 100 \\
\hline
\end{tabular}

Source: Fieldwork, July 2019

Table 9 shows outcomes on whether incorporation of the technology makes the discharge of their duties easier and faster. The results indicate that most of the respondents (44.4\%) said to a large extent it has made their work faster and easier. While $28.9 \%$ of the respondents said to some extent, $15.6 \%$ also said to a very large extent, it has made them discharge their duties easier and faster. Few of them (11.1\%) said to a very small extent, the system has enabled them to discharge their duties faster and easier.

Table 10: Benefits to users with the use of the technology

\begin{tabular}{|l|c|c|}
\hline Independent Variables & Mean & Std. Dev. \\
\hline The completeness of patient information & 5.0000 & .0000 \\
\hline EMR helps monitor the progress of in-patients & 4.1379 & .44111 \\
\hline $\begin{array}{l}\text { Has helped effective interaction or interface of all } \\
\text { units involved in patient care }\end{array}$ & 3.0931 & .77364 \\
\hline Ensured both user and patient satisfaction & 4.9655 & .18570 \\
\hline $\begin{array}{l}\text { Reduced patient waiting time } \\
\begin{array}{l}\text { Reduced staff hurdles associated with manual } \\
\text { system }\end{array}\end{array}$ & 4.9310 & .25788 \\
\hline
\end{tabular}

$[S A=5, A=4, U=3, D=2, S D=1]$

Source: Field survey (2019)

Table 10 shows that there was a general affirmation to the statement affirming that EHR technology provides more complete information about patients (5.0000). From the results, the respondents agreed to the statements that EMR helps monitor the progress of in-patients (4.1379). Concerning the technology has helped to promote effective interaction or interface of all units involved in patient care, respondents (3.0931) were unsure regarding the statement. The results further indicate that the respondents strongly agreed (4.9655) with the statement that the 
International Journal of Multidisciplinary Studies and Innovative Research

\author{
Publisher: Catholic University College of Ghana \\ ISSN: 2737-7172 (0), ISSN: 2737-7180 (P) \\ DOI: $10.53075 /$ ljmsirq5930716 \\ DOI Url: http://doi.org/10.53075/ljmsirq5930716
}

system has ensured both user and patient satisfaction. Again, there was strong agreement (4.9310) to the statement that the technology has reduced patient waiting time in accessing health care services at the hospital. Furthermore, the respondents agreed (4.0793) to the statement that staff hurdles as far as the use of the manual system have been reduced by the new technology.

Table 11: Effects of EMR usage in improving healthcare provision

\begin{tabular}{|l|c|c|}
\hline Effects & No. & Percent \\
\hline Improved accuracy and quality of patient data & 4.9655 & .18570 \\
\hline Enhanced staff access to patient's information with ease & 5.0000 & .0000 \\
\hline Enabled users to share to facilitate better care & 5.0000 & .0000 \\
\hline $\begin{array}{l}\text { Improved quality of care or services at all times due to } \\
\text { available information about the patients }\end{array}$ & 4.9655 & .18570 \\
\hline $\begin{array}{l}\text { Provide timely statistical data, in an efficient manner, to } \\
\text { all staff }\end{array}$ & 5.0000 & .0000 \\
\hline $\begin{array}{l}\text { Helped management in administrative and financial } \\
\text { reporting (as revenue is being monitored) }\end{array}$ & 4.9655 & .18570 \\
\hline
\end{tabular}

Source: Field survey, July (2019)

Table 11 depicts the effects of the HER on the general healthcare administration in the hospital. The results indicate that all the respondents (5.0000) each supported the statements that the technology has enhanced staff access to patient's information with ease, provide timely statistical data, efficiently efficiently, to all staff, and enabled users to share to facilitate better care. Others said it has improved the accuracy and quality of patient data, helped the management in administrative and financial reporting, and also improved the quality of care or services at all times due to available information about the patients (4.9655). In measuring the extent to which the adoption of the technology has improved the health care delivery provided by the hospital, the engaged the staff to know their perceptions about the system, the effect on general health care delivery and the general benefits offered by the system. The general perception of the staff of the system indicated that most of the respondents (46.7\%) said the system is accessible (accessibility). One-fifth of the respondents said it is accurate (accuracy). Reducing errors came next as $17.8 \%$ of the respondents mentioned that as a feature. Others, $11.1 \%$ said the system is efficient (efficiency) while $4.4 \%$ said the technology is reliable (reliability).

Benefits relating to the use of the system showed that the system in its current form offers many benefits. From the results, the respondents agreed to the statements that EMR helps monitor the progress of in-patients (4.1379). With regard to the technology has helped to promote effective interaction or interface of all units involved in patient care, respondents (3.0931) were unsure regarding the statement. The results further indicate that the respondents strongly agreed (4.9655) with the statement that the system has ensured both user and patient satisfaction. Again, there was strong agreement (4.9310) to the statement that the technology has reduced patient waiting time in accessing health care services at the hospital. Furthermore, the respondents agreed (4.0793) to the statement that staff hurdles as far as the use of the manual system have been reduced by the new technology. The findings agree with Hillestad et al. (2005) that conducted a study on the likely benefits and reduced cost-benefit of Electric Health Records adoption revealed that EHR implementation would help save health facilities' revenue. The benefits of EHR in improving patient security and quality healthcare delivery cannot be overemphasized.

The general effects of the HER on the general healthcare administration in the hospital reflect that of satisfaction with the system and improvement in the health care delivery in the provision of quality service. The results indicate that all the respondents (5.0000) each supported the statements that the technology has enhanced staff access to patient's information with ease, provide timely statistical data, in an efficient manner, to all staff, and enabled users 
International Journal of Multidisciplinary Studies and Innovative Research

\author{
Publisher: Catholic University College of Ghana \\ ISSN: 2737-7172 (0), ISSN: $2737-7180(\mathrm{P})$ \\ DOI: $10.53075 /$ ljmsirq5930716 \\ DOI Url: http://doi.org/10.53075/ljmsirq5930716
}

to share to facilitate better care. Others said it has improved the accuracy and quality of patient data, helped the management in administrative and financial reporting, and also improved quality of care or services at all times due to available information about the patients (4.9655). The findings support various studies in Ghana in relation to the use of electronic health records. For example, the finding agreed with Owusu (2016) that the utilization of Electronic Health Records has brought an improvement in the area of care with the adoption of EHR system and that patients time at the hospital has gone down by Forty percent (40\%). There is also improvement report generation within a short time. Another study that the findings of this study support is Kesse-Tachi (2016) that found the system helping in administrative, patient record, pharmaceutical/prescriptive system, procurement and supply chain and the laboratory management systems.

Inherent challenges of the deployment of electronic health records in the hospital

Various challenges have been identified with the deployment of the technology. This section highlights the objective 4 of the study and presents the results from the data analyzed.

Table 12: System Inherent Challenges

\begin{tabular}{|l|c|c|}
\hline Challenges & No & Percent \\
\hline Frequent Power outages & 50 & 100.0 \\
\hline Persistent network problem & 26 & 42.0 \\
\hline Lack of technical know-how of users & 10 & 20.0 \\
\hline Accessibility issues (log in) & 41 & 82.0 \\
\hline Limited computer skills by users & 10 & 20.0 \\
\hline Total & 50 & 100 \\
\hline
\end{tabular}

Source: Fieldwork, July 2019

Table 12 shows the various challenges inherent in the system and affecting the effective utilization of the system. Multiple responses were generated during the process of collecting the data. The results indicate that all the respondents $(100 \%)$ said frequent power outages is the main challenge they are confronted with. There is an issue of $\log$ in challenges as $82 \%$ of the respondents indicated. Forty-two percent of the respondents mentioned persistent network problems experienced by the system. One-fifth of the respondents also mentioned limited computer skills by the users and the lack of technical know-how from the users. The findings agree with Borketey (2017) that indicated the setbacks confronting eHealth implementation including the lack of ICT Infrastructure; Electric Power Supply; Basic ICT Knowledge or Skills; Resistance to New Technology; the Internet; Financial and Sustainability Issues. Again, the findings support the WHO (2012) that identified other constraints to the adoption of Electronic Health Records in Africa including the erratic electricity supply and inadequate human resource capacity. Moreover, in confirming the study of Odekunle et al. (2017) that found factors that prevent the acceptance of EHR as inadequate power supply poor internet connectivity, primary users' limited computer skills, and lack of robust healthcare infrastructure.

\title{
Measures management has employed to deal with the inherent challenges
}

Respondents were asked to indicate how the challenges are being addressed by management to experience the full benefits that the technology bring. This subsection presents the results from the analyzed data collected from survey staff and management of the hospital. 
International Journal of Multidisciplinary Studies and Innovative Research

Publisher: Catholic University College of Ghana

ISSN: 2737-7172 (0), ISSN: 2737-7180 (P)

DOI: $10.53075 /$ ljmsirq5930716

DOI Url: http://doi.org/10.53075/ljmsirq5930716

Table 13: Measures to address the inherent challenges

\begin{tabular}{|l|c|c|}
\hline Measures & No & Percent \\
\hline Procurement of standby generator & 31 & 62.0 \\
\hline Procurement high-speed internet connectivity & 2 & 4.0 \\
\hline Training of personnel & 3 & 6.0 \\
\hline Consistent update of the system to address log in challenges & 10 & 20.0 \\
\hline Procurement of other IT logistics (software programmes, accessories) & 4 & 8.0 \\
\hline Total & 50 & 100 \\
\hline
\end{tabular}

Source: Fieldwork, 2019

Table 13 displays that the majority of respondents (62\%) said management has procured a standby generator to solve the power cut challenges. One-fifth of the respondents mentioned the need for an update of the system to address the log in problems experienced in the system. Others, 8\% mentioned the purchase of IT logistics and accessories to boost the system to function effectively and efficiently. While $6 \%$ of the respondents said a regular update of personnel through in-service training, 4\% mentioned management buying high-speed internet connectivity to address network issues.

\section{CONCLUSION}

The objective of this research study was to assess Electronic Health Records implementation at Presbyterian Hospital in Dormaa Ahenkro of Bono Region. The study confirms the Venkatesh, Morris and Davis UTAUT model, which stipulates that the use and adoption of EHR are associated with factors including expectancy of performance, expectancy or effort, facilitating conditions and social influence revealed that they all influence management of the hospital to adopt the technology. As observed in the study, the use and adoption of EHR systems were integrated in all the units or departments of the hospital specifically in the management of patient records, dosage from the pharmacy and results from the laboratory while the consulting and wards departments. There is also the administrators' use of the system mostly in the billing, financial systems and reporting. In conclusion, some strategies need to be put in place as revealed by the study including reliable power, backup system and system upgrade all the time to improve healthcare delivery to the people and overall service delivery.

\section{Recommendations}

Based on the findings, outcomes and drawn conclusions, the following recommendations are put forward:

i. Successful implementation of the EHR is equally dependent on healthcare professionals and other staff's skills and knowledge in using the computer. The study revealed that some staff are still not able to use the system because they do not routinely use computers. Management particularly the IT and the HR should collaborate to organize frequent in-service training for users. Thus, users should be trained to acquire the skills and knowledge needed in using the EHR effectively and independently.

ii. Aside organizing in-service staff training, management can institute the learning of computer skills programme for personnel to help address the situation. Management needs to encourage and support the staff to overcome their reluctance

iii. In order to ensure the system stands against loss, destruction, interfering and unlawful use of EHR system, a system safeguards must be in place. Management through the IT unit should consider procurement of an efficient backup system, regular change of passwords to maintain the security of the system.

iv. In addition, management through the IT unit should put in place incident reporting and response mechanisms, to ensure continuous monitoring and evaluation of the system to make all users comply with the standards set. 


\title{
International Journal of Multidisciplinary Studies and Innovative Research
}

\author{
Publisher: Catholic University College of Ghana \\ ISSN: 2737-7172 (0), ISSN: 2737-7180 (P) \\ DOI: $10.53075 /$ ljmsirq5930716 \\ DOI Url: http://doi.org/10.53075/ljmsirq5930716
}

\section{ACKNOWLEDGMENT}

I would like to express my gratitude to Prof. Daniel Obeng-Ofori, President of Catholic University College for his suggestions and directions, the management and staff of the the Presbyterian Hospital of Dormaa Ahenkro for their cooperation and assistance. I also thank the editorial board of the International Journal of Multidisplinary Studies and Innovative Research for their constructive suggestions.

\section{REFERENCES}

Abul-Husn, N. S., \& Kenny, E. E. (2019). Personalized Medicine and the Power of Electronic Health Records. Cell, 177(1), 58-69. https://doi.org/10.1016/j.cell.2019.02.039

Agniel, D., Kohane, I. S., \& Weber, G. M. (2018). Biases in electronic health record data due to processes within the healthcare system: Retrospective observational study. BMJ, k1479. https://doi.org/10.1136/bmj.k1479

Baumann, L. A., Baker, J., \& Elshaug, A. G. (2018). The impact of electronic health record systems on clinical documentation times: A systematic review. Health Policy, 122(8), 827-836. https://doi.org/10.1016/j.healthpol.2018.05.014

Cortina, J. M. (2020). On the Whys and Hows of Quantitative Research. Journal of Business Ethics, 167(1), 1929. https://doi.org/10.1007/s10551-019-04195-8

Fragidis, L. L., \& Chatzoglou, P. D. (2018). Implementation of a nationwide electronic health record (EHR): The international experience in 13 countries. International Journal of Health Care Quality Assurance, 31(2), 116-130. https://doi.org/10.1108/IJHCQA-09-2016-0136

Garcelon, N., Burgun, A., Salomon, R., \& Neuraz, A. (2020). Electronic health records for the diagnosis of rare diseases. Kidney International, 97(4), 676-686. https://doi.org/10.1016/j.kint.2019.11.037

Hansen, M. B., Kidholm, K., Nøhr, C., \& Elmholdt, K. T. (n.d.). Model for Evaluating the Implementation of a Third Generation EHR System. 8.

Rambaud-Althaus, C., Shao, A., Samaka, J., Swai, N., Perri, S., Kahama-Maro, J., Mitchell, M., D’Acremont, V., \& Genton, B. (2017). Performance of Health Workers Using an Electronic Algorithm for the Management of Childhood Illness in Tanzania: A Pilot Implementation Study.

The American Journal of Tropical Medicine and Hygiene, 96(1), 249-257. https://doi.org/10.4269/ajtmh.150395

Zhang, J., Kowsari, K., Harrison, J. H., Lobo, J. M., \& Barnes, L. E. (2018). Patient2Vec: A Personalized Interpretable Deep Representation of the Longitudinal Electronic Health Record. IEEE Access, 6, 6533365346. https://doi.org/10.1109/ACCESS.2018.2875677 